\title{
DESAIN KONSEPTUAL PERISAI RADIASI REAKTOR RRI-50
}

\author{
Amir Hamzah dan Iman Kuntoro \\ Pusat Teknologi dan Keselamatan Reaktor Nuklir BATAN \\ Kawasan Puspiptek Gedung No. 80, Serpong, Tangerang Selatan \\ email: ahamzah@batan.go.id \\ Diterima editor: 15 Mei 2015 \\ Direvisi editor: 3 Juni 2015 \\ Disetujui untuk publikasi: 18 Juni 201
}

\begin{abstract}
ABSTRAK
DESAIN KONSEPTUAL PERISAI RADIASI REAKTOR RRI-50. Salah satu parameter yang harus dipenuhi dalam mendesain reaktor nuklir adalah desain perisai radiasi yang dapat menjamin keamanan dan keselamatan radiasi bagi pekerja dan masyarakat sekitar. Pada penelitian ini dilakukan desain perisai radiasi RRI-50 dengan elemen bakar berjenis U9Mo-Al berkerapatan tinggi dengan tipe pelat sebanyak 21 buah dan berdimensi seperti elemen bakar RSG-GAS tapi panjang aktifnya $70 \mathrm{~cm}$. Konfigurasi teras terdiri dari 16 elemen bakar dan 4 elemen kendali serta 5 posisi iradiasi sehingga membentuk matriks $5 \times 5$. Tujuan dari penelitian ini adalah mendesain perisai radiasi dan menentukan distribusi laju dosis di daerah kerja dan di lingkungan reaktor RRI-50. Tahapan awal penelitian adalah perhitungan kuat sumber dan inventori bahan radioaktif teras reaktor dengan mensimulasikan operasi $50 \mathrm{MW}$ selama 20 hari tiap siklus menggunakan program ORGEN2.1. Berdasarkan kuat sumber tersebut dan model yang dibuat menggunakan program VisEd, maka dilakukan analisis penentuan parameter perisai radiasi secara iteratif menggunakan program MCNPX. Pada tahap akhir, dilakukan analisis distribusi laju dosis di seluruh ruang di dalam dan di luar gedung reaktor juga menggunakan program MCNPX. Hasil yang diperoleh menunjukkan bahwa ketinggian permukaan air adalah $1000 \mathrm{~cm}$ dan kombinasi $90 \mathrm{~cm}$ beton berat dan $60 \mathrm{~cm}$ beton biasa dapat digunakan sebagai perisai biologi. Desain perisai tersebut mereduksi laju dosis menjadi $0,05 \mu \mathrm{Sv} / \mathrm{jam}$ di Balai Operasi sementara di Balai Eksperimen dan di luar gedung reaktor menjadi 4,2 $\mu \mathrm{Sv} / \mathrm{jam}$ dan $0,03 \mu \mathrm{Sv} / \mathrm{jam}$ pada saat reaktor beroperasi. Hasil penelitian juga menunjukkan pemasagan perisai tambahan setebal $280 \mathrm{~cm}$ berjarak $300 \mathrm{~cm}$ di depan tabung berkas neutron radial yang terbuka mereduksi laju dosis gamma dan neutron menjadi $3,3 \mu \mathrm{Sv} / \mathrm{jam}$ dan $3,1 \times 10^{-11} \mu \mathrm{Sv} / \mathrm{jam}$. Hasil-hasil penelitian ini menunjukkan bahwa desain perisai radiasi yang dibuat membuat reaktor RRI-50 menjadi aman dari bahaya radiasi bagi pekerja dan masyarakat sekitarnya.
\end{abstract}

Kata kunci : Perisai radiasi, laju dosis, keselamatan radiasi, RRI-50.

\section{ABSTRACT}

RADIATION SHIELDING CONSEPTUAL DESIGN OF RRI-50 REACTOR. One of the parameters that must be met in the design of nuclear reactors is radiation shielding design to ensure the security and safety of workers and the surrounding community. This study has been conducted to design radiation shielding of RRI50 with high density U9Mo-Al fuel elements that consist of 21 pieces of plate type fuel elements with dimension as same as RSG-GAS fuel elements but the active length is $70 \mathrm{~cm}$. Core configurations consist of 16 fuel elements and 4 control elements and 5 irradiation positions to form a matrix of $5 \times 5$. The objective of this research is to design radiation shielding and determine the distribution of dose rates in the working area and the environment of RRI-50 reactor. The early stages of this research is to calculate source strength and inventory of radioactive materials within the reactor core with one operation pattern cycle of $50 \mathrm{MW}$ for 20 days using ORGEN2.1 program. Based on core source strength and models that are created using the VisEd software, the analysis parameter of the shielding was determined iteratively using MCNPX program. In the final stage, an analysis of the dose rate distributions in the whole space inside and outside the reactor building was conducted also using MCNPX program. The results show that the height of the water surface is $1000 \mathrm{~cm}$ and the combination of heavy concrete thickness of $90 \mathrm{~cm}$ and ordinary concrete thickness of $60 \mathrm{~cm}$ can be used as an biological shield. This design can reduce the dose rate to $0.05 \mu \mathrm{Sv} / \mathrm{h}$ in the Operations Room while in the Experiments Room and outside the reactor building to $4.2 \mu \mathrm{Sv} / \mathrm{h}$ and $0.03 \mu \mathrm{Sv} / \mathrm{h}$ during reactor operation. The results also suggest that the installation of additional radiation shield of $280 \mathrm{~cm}$ thickness within $300 \mathrm{~cm}$ in front of the open radial neutron beam tube can reduce gamma and neutron dose rate to $3.3 \mu \mathrm{Sv} / \mathrm{h}$ and $3,1 \times 10^{-11} \mu \mathrm{Sv} / \mathrm{h}$. The results of this study indicate that the radiation shield design is made to make reactor RRI-50 to be safe from radiation hazards to workers and surrounding communities.

Keywords : Radiation shielding, dose rates, radiation safety, RRI-50. 


\section{PENDAHULUAN}

Sebagai institusi litbang nuklir di Indonesia, BATAN telah berpengalaman mengoperasikan tiga reaktor riset yaitu reaktor Kartini di PTAPB-BATAN Yogyakarta, reaktor TRIGA 2000 di PTNBR-BATAN Bandung dan reaktor RSG-GAS Serpong. Mengingat reaktor Kartini dan reaktor TRIGA 2000 telah mendekati masa akhir operasinya, maka perlu dilakukan langkah-langkah untuk membangun sebuah reaktor riset baru sebagai penggantinya. Tujuan pembangunan reaktor riset baru antara lain adalah agar terjamin kemandirian produksi radioisotop untuk pasar lokal dan luar negeri, meningkatkan litbang nuklir serta peningkatan kemampuan SDM di bidang nuklir. Disamping itu, pemanfaatan metode neutron transmutation doping dalam memproduksi semikonduktor melalui iradiasi silicon ingot dapat memberikan dampak devisa cukup menjanjikan. Pembangunan dan pengoperasian sebuah reaktor riset secara garis besar melalui tahapan desain konseptual, desain dasar, desain rinci, konstruksi, komisioning dan operasi hingga dekomisioning. Sebagai tahapan awal dari serangkaian tahapan tersebut, hingga saat ini PTRKN-BATAN telah berhasil melakukan penyusunan dokumen desain konseptual reaktor riset inovatif yang didahului dengan tersusunya dokumen kriteria pengguna ( $\mathrm{UCD}=$ user criteria document) yang berisi spesifikasi utama reaktor riset inovatif. Salah satu parameter di dalam spesifikasi utama tersebut adalah adanya jaminan keamanan dan keselamatan radiasi bagi pekerja dan lingkungan merupakan persyaratan utama yang ditetapkan oleh BAPETEN dan harus dipenuhi dalam mendesain, membangun dan mengoperasikan suatu reaktor nuklir.

Pada tahun 2013, penulis telah melakukan penelitian mengenai desain awal perisai radiasi dan analisis laju dosis di daerah kerja reaktor riset inovatif (RRI) menggunakan MCNPX [1]. Desain awal perisai radiasi reaktor RRI tersebut masih sangat sederhana dan model reaktor masih mengikuti reaktor RSG-GAS dengan dengan panjang bahan bakar $60 \mathrm{~cm}$ dan daya reaktor $20 \mathrm{MWth}[2,3,4]$. Pada akhir tahun 2014, desain konseptual teras RRI-50 telah berhasil dibuat melalui beberapa pilihan bentuk dan tingkat muat bahan bakar teras alternatif [2,3,5]. Desain konseptual teras RRI-50 tersebut menggunakan bahan bakar dengan densitas $3,66 \mathrm{~g} / \mathrm{cm}^{3}$, panjang bahan bakarnya $70 \mathrm{~cm}$, daya reaktor sebesar 50 MWth dengan panjang siklus 20 hari $[4,5,6]$. Untuk mendapatkan hasil yang lebih konservatif, pada penelitian ini digunakan bahan bakar dengan densitas yang lebih tinggi yaitu 8,3 $\mathrm{g} / \mathrm{cm}^{3}$. Hal itu juga yang menjadi salah satu perbedaan dengan reaktor CARR [7] buatan China. Dengan demikian sumber radiasi yang berasal dari reaktor RRI-50 menjadi lebih besar dibandingkan dengan teras berbahan bakar berdensitas yang lebih rendah. Konsekuensi dari sumber radiasi yang lebih besar akan mengakibatkan desain perisai radiasinya juga akan mengalami perubahan agar tetap terjamin keamanan dan keselamatan radiasi terhadap pekarja dan masyarakat sekitar. Tujuan dari makalah ini adalah untuk menyajikan hasil desain konseptual perisai radiasi dan penentuan distribusi laju dosis di daerah kerja serta lingkungan reaktor RRI-50. Untuk mencapai tujuan tersebut maka dilakukan beberapa tahapan analisis di dalam suatu kerangka penelitian. Analisis dimulai dari perhitungan kuat sumber dan inventori bahan radioaktif teras reaktor berdasarkan komposisinya dengan mengikuti pola operasinya selama 6 (enam) siklus menggunakan program ORGEN2.1 [8]. Langkah berikutnya adalah membuat model teras, perisai hingga gedung reaktor sesuai dengan ukuran geometri yang sebenarya menggunakan perangkat lunak Vised yang merupakan bagian dari paket program MCNPX. Berdasarkan model yang dibuat tersebut, maka secara iteratif dilakukan analisis penentuan parameter perisai radiasi reaktor menggunakan program MCNPX. Seperti diketahui, bahwa program MCNPX merupakan program komputer berbasis monte-carlo yang telah digunakan secara luas dan telah dilakukan validasi dengan model reaktor RSG-GAS [9] dengan hasil yang cukup dekat dengan pengukuran. Setelah diperoleh parameter perisai radiasi reaktor yang optimum, maka selanjutnya dilakukan analisis distribusi laju dosis di beberapa ruang kerja di dalam gedung reaktor dan di luar gedung reaktor yang juga menggunakan program MCNPX. Dengan demikian dapat ditentukan identifikasi ruangan berdasarkan paparan radiasi sehingga prinsip ALARA dapat diterapkan secara efektif dan efisien untuk menjamin keamanan dan keselamatan radiasi terutama bagi pekerja. Hasil penelitian yang diharapkan adalah diperolehnya suatu desain perisai radiasi reaktor RRI-50 yang aman bagi pekerja dan masyarakat sekitar yang memenuhi ketentuan BAPETEN dengan batas laju dosis masing-masing sebesar $10 \mu \mathrm{Sv} / \mathrm{jam}$ dan $0,1 \mu \mathrm{Sv} / \mathrm{jam}[10]$. 


\section{METODOLOGI}

\section{Kriteria Desain Perisai Radiasi}

Dalam melakukan desain perisai radiasi reaktor RRI-50, diterapkan kriteria batas keselamatan radiasi maksimum yang boleh diterima oleh pekerja radiasi dan oleh masyarakat sekitar. Ketentuan tersebut dimuat di dalam peraturan Kepala BAPETEN No. 4 Tahun 2013 tentang Proteksi dan Keselamatan Radiasi dalam Pemanfaatan Tenaga Nuklir [10] yang antara lain berisi :

a. Nilai batas dosis efektif rata-rata untuk pekerja sebesar $20 \mathrm{mSv} /$ tahun (dua puluh milisievert per tahun), bila dikonversi menjadi laju dosis per jam adalah $10 \mu \mathrm{Sv} / \mathrm{jam}$ (sepuluh mikrosievert per jam).

Faktor konversi yang digunakan adalah per hari dihitung 8 jam kerja, per minggu dihitung 5 hari kerja dan per tahun dihitung 50 minggu. Maka bila desain perisai yang dibuat dapat mereduksi laju dosis menjadi lebih rendah dari $10 \mu \mathrm{Sv} / \mathrm{jam}$, maka dalam setahun seorang pekerja di luar perisai tersebut tidak akan mencapai batas dosis efektif yang ditentukan.

b. Nilai batas dosis efektif untuk anggota masyarakat sebesar $1 \mathrm{mSv} /$ tahun (satu milisievert per tahun), bila dikonversi menjadi laju dosis per jam maksimum sebesar $0,1 \mu \mathrm{Sv} / \mathrm{jam}$ (seper sepuluh mikrosievert per jam).

Faktor konversi yang digunakan di sini adalah perhari selama 24 jam dan pertahun sepanjang 365 hari. Maka bila desain perisai yang dibuat dapat mereduksi laju dosis hingga lebih rendah dari $0,1 \mu \mathrm{Sv} / \mathrm{jam}$, maka anggota masyarakat di sekitarnya tidak akan mendapat paparan radiasi yang mencapai batas dosis efektif yang ditentukan tersebut.

\section{Deskripsi Teras Reaktor RRI-50}

\section{a. Elemen Bakar dan Elemen Kendali Reaktor RRI-50}

Seperti disebutkan di dalam pendahuluan, desain teras RRI-50 menggunakan bahan bakar jenis molybdinum (U9Mo-Al) pengkayaan rendah (kurang $20 \%$ ) dengan densitas $3,66 \mathrm{~g} / \mathrm{cm}^{3} \mathrm{di}$ dalam tiap elemen bakarnya. Reaktor RRI-50 menggunakan bahan bakar jenis pelat (MTR type), dengan pendingin air ringan dan reflektor air berat dan elemen bakar kendali berbentuk kotak. Batang kendali menggunakan bahan paduan Ag-In-Cd tipe follower. Tabel 1 memuat data geometri perangkat elemen bakar reaktor RRI-50. Gambar 1 (a) dan (b) masing-masing menunjukkan dimensi perangkat elemen bakar (EB) dan elemen kendali (EK). Namun untuk mendapatkan hasil yang lebih konservatif, pada penelitian ini digunakan bahan bakar dengan densitas yang lebih tinggi yaitu $8,3 \mathrm{~g} / \mathrm{cm}^{3}$. Sedangkan parameter yang lain tetap seperti yang tertera pada Tabel 1 .

Tabel 1. Data geometri perangkat elemen bakar dan elemen kendali reaktor RRI-50 [2,3,5]

\begin{tabular}{lc}
\hline Jenis & $M T R$ \\
\hline Ketebalan pelat bahan bakar, cm & 0,13 \\
Dimensi zona aktif (meat), cm & $0,054 \times 6,275 \times 70,0$ \\
Ketebalan kelongsong bahan bakar, cm & 0,038 \\
Lebar kanal pendingin, cm & 0,255 \\
Jumlah pelat elemen bakar per elemen bakar standar & 21 \\
Jumlah pelat elemen bakar per elemen bakar kendali & 15 \\
Dimensi elemen bakar standar (EB) dan kendali (EK), cm & $7,71 \times 8,1 \times 70,0$ \\
Material kelongsong & $\mathrm{AlMg} 2$ \\
Material pelat sisi & $\mathrm{AlMg} 1$ \\
Jumlah elemen bakar standar di dalam teras & 16 \\
Jumlah elemen bakar kendali pada teras & 4 \\
Material bahan bakar & $\mathrm{U} 9 \mathrm{Mo}-\mathrm{Al}$ \\
Densitas bahan bakar, g/cm ${ }^{3}$ & 3,66 \\
Pengkayaan ${ }^{235} \mathrm{U}_{\text {, }}$ ( & 19,75 \\
Material penyerap & $\mathrm{Ag}-\mathrm{In}-\mathrm{Cd}$ \\
Ketebalan penyerap, cm & 0,338 \\
Material kelongsong penyerap & $\mathrm{SS}-321$ \\
Ketebalan kelongsong penyerap, cm & 0,085 \\
Daya, MWth / panjang siklus, hari & $50 / 20$ \\
\hline
\end{tabular}




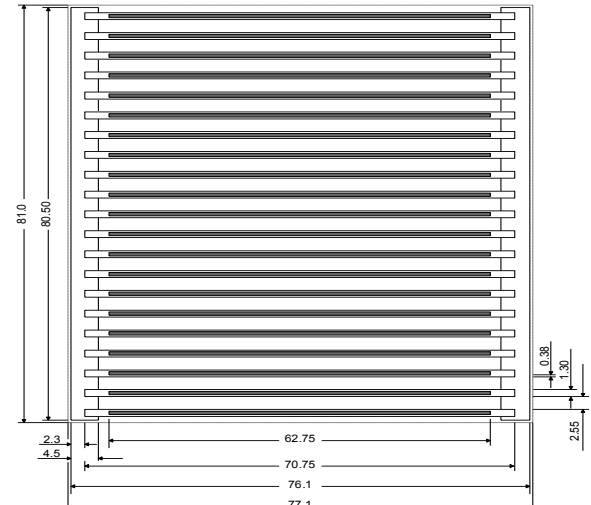

(a)

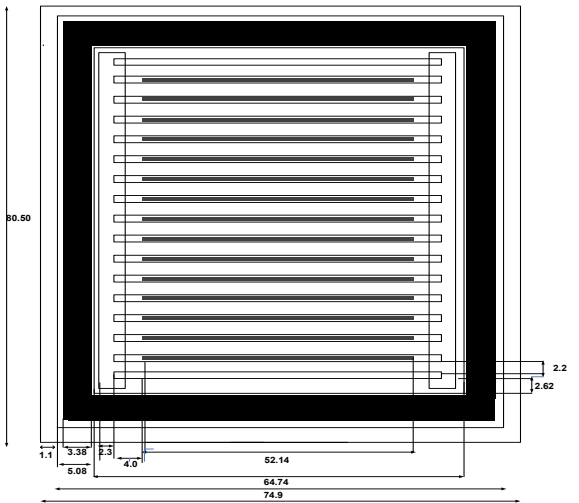

(b)

Gambar 1. Perangkat bahan bakar (a) dan elemen kendali (b) reaktor RRI-50 [2,3,6]

\section{b. Konfigurasi dan Parameter Teras Reaktor RRI-50}

Konfigurasi teras dengan kisi 5 x 5 dengan 16 bahan bakar dan 4 batang kendali serta 5 buah posisi iradiasi yang berisi air seperti yang ditunjukkan dalam Gambar 2. Teras aktif RRI-50 panjang 38,55 $\mathrm{cm}$ dan lebar $40,5 \mathrm{~cm}$ dengan diameter reflektor tabung $\mathrm{D}_{2} \mathrm{O}$ sebesar $2 \mathrm{~m}$ dengan tinggi $1,5 \mathrm{~m}$ dan diameter kolam $5 \mathrm{~m}$.

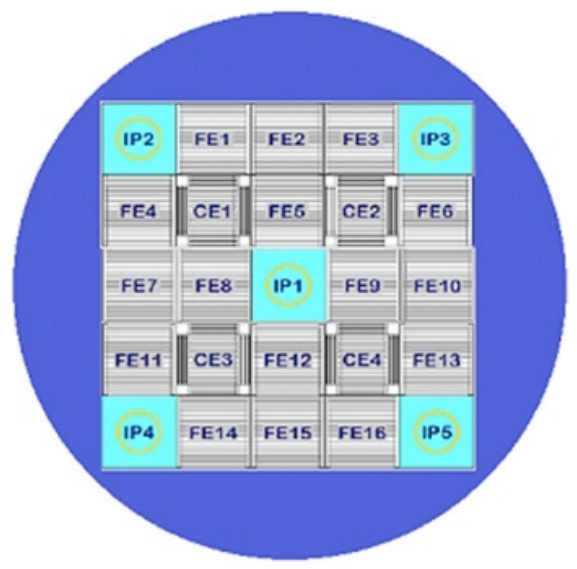

$\mathrm{FE}=$ elemen bakar, $\mathrm{CE}=$ elemen kendali, $\mathrm{IP}=$ posisi iradiasi

Gambar 2. Konfigurasi teras RRI-50 [2,3,6]

Dalam analisis paparan radiasi reaktor RRI-50 ini digunakan densitas bahan bakar yang paling tinggi yang pernah dianalisis pada beberapa publikasi yaitu $8,3 \mathrm{~g} / \mathrm{cm}^{3}[2,3,6]$. Hal itu dilakukan untuk mendapatkan hasil analisis yang konservatif. Seperti diketahui, semakin tinggi tingkat muat teras reaktor maka akan semakin tinggi kuat sumbernya karena akan semakin banyak bahan fisil yang memancarkan radiasi gamma saat menangkap neutron dan produk fisi yang juga sebagai pemancar radiasi gamma. Disamping itu, karena beberapa publikasi tersebut di atas menyebutkan adanya kemungkinan penerapan tingkat muat hingga $8,3 \mathrm{~g} / \mathrm{cm}^{3}$ di dalam reaktor RRI50 maka penelitan ini juga mengantisipasi kemungkinan tersebut.

\section{Langkah Perhitungan}

a. Perhitungan komposisi dan kuat sumber teras RRI-50. Perhitungan komposisi dilakukan berdasarkan data-data teras RRI-50 yang dihitung ke dalam satuan persen berat. Kuat sumber teras tangkapan radiatif dan fisi spontan dihitung secara analitik sedangkan kuat sumber teras peluruhan zat radioaktif dihitung menggunakan paket program ORIGEN2.1. Perhitungan kuat sumber teras tersebut dilakukan dengan daya reaktor 50 MWth dan kondisi fraksi bakar maksimum yaitu setelah beroperasi 6 siklus ( 1 siklus $=20$ hari) dengan waktu padam 24 hari di dalam dan diantara siklus. 
b. Pemodelan teras beserta perisai radiasi reaktor RRI-50, dilakukan menggunakan paket program VisEd. Pemodelan dilakukan berdasarkan komposisi dan ukuran dimensi semua meterial yang dibahas dalam analisis ini. Bila pemodelan yang dibuat pada tahap ini belum benar, maka analisis pada tahap berikutnya tidak dapat dilakukan.

c. Penentuan tebal perisai radiasi reaktor RRI-50. Penentuan tebal perisai dilakukan menggunakan paket program MCNPX secara iteratif hingga dipenuhi kriteria desain yang disebutkan di atas.

d. Analisis distribusi laju dosis radiasi di daerah kerja dan di luar gedung reaktor RRI-50 menggunakan paket program MCNPX. Daerah kerja yang dimaksud setidaknya adalah ruang Balai Eksperimen dan Balai Operasi.

\section{HASIL DAN PEMBAHASAN}

\section{Komposisi Teras Reaktor RRI-50}

Seperti diutarakan di atas, elemen bakar teras reaktor RRI-50 berjenis U9Mo-Al berkerapatan $3,66 \mathrm{~g} / \mathrm{cm}^{3}$, namun dalam analisis keselamatan radiasi ini digunakan kerapatan yang lebih tinggi yang secara teoritis dapat dicapai yaitu $8,3 \mathrm{~g} / \mathrm{cm}^{3}$ agar diperoleh tingkat keselamatan radiasi yang lebih konservatif. Perhitungan komposisi teras dan komponen reaktor lainnya dengan konfigurasi teras yang dipaparkan di atas dibuat kedalam satuan persen berat berdasarkan data-data teras reaktor RRI-50 dan dari data yang terdapat di dalam Compendium Engineering on Radiation Shielding dimuat di dalam Tabel 3. Perbedaan beton berat dan beton biasa terutama terletak pada kandungan oksigen, silikon, besi dan barium. Pada beton biasa lebih banyak mengandung oksigen dan silikon sedangkan beton berat lebih banyak mengandung besi dan barium. Seperti diketahui, dibandingkan dengan oksigen dan silikon, unsur besi dan barium memiliki tampang lintang yang lebih besar dan kerapatan yang lebih tinggi, sehingga kemampuannya sebagai perisai radiasi lebih baik. Akan tetapi tentunya beton berat berharga lebih mahal, sehingga perlu ditentukan kombinasi jenis dan dimensi perisai yang optimal.

Tabel 3. Komposisi teras, Al-alloy, beton, air, air berat dan udara (w/o) beserta densitasnya.

\begin{tabular}{|c|c|c|c|c|c|c|c|}
\hline Unsur & $\begin{array}{c}\text { Teras } \\
1,970651\end{array}$ & $\begin{array}{c}\text { Al-alloy } \\
2,7\end{array}$ & $\begin{array}{c}\mathrm{H}_{2} \mathrm{O} \\
0,9983\end{array}$ & $\begin{array}{c}\mathrm{D}_{2} \mathrm{O} \\
1,107\end{array}$ & $\begin{array}{c}\text { Beton } \\
\text { biasa } \\
2,32\end{array}$ & $\begin{array}{c}\text { Beton } \\
\text { berat } \\
3,53\end{array}$ & $\begin{array}{c}\text { Udara } \\
0,00118\end{array}$ \\
\hline U235 & 0,071505 & & & & & & \\
\hline U238 & 0,290544 & & & & & & \\
\hline Mo & 0,035807 & & & & & & \\
\hline $\mathrm{Mg}$ & 0,004315 & 0,00900 & & & & & \\
\hline $\mathrm{Si}$ & 0,001308 & 0,01025 & & & 0,337 & 0,0573 & \\
\hline $\mathrm{Cu}$ & 0,000619 & 0,00700 & & & & & \\
\hline Mn & 0,001062 & 0,00700 & & & & & \\
\hline $\mathrm{Fe}$ & 0,001087 & 0,00500 & & & 0,014 & 0,1647 & \\
\hline $\mathrm{Cr}$ & 0,000645 & 0,00150 & & & & & \\
\hline $\mathrm{Zn}$ & 0,000506 & 0,00200 & & & & & \\
\hline $\mathrm{Ti}$ & 0,000253 & 0,00100 & & & & & \\
\hline Al & 0,285938 & 0,95725 & & & 0,034 & & \\
\hline $\mathrm{O}$ & 0,272124 & & 0,888085 & 0,798867 & 0,532 & 0,2824 & 0,218881 \\
\hline $\mathrm{H}$ & 0,034288 & & 0,111915 & & 0,010 & 0,0014 & 0,001119 \\
\hline H-2 & & & & 0,201133 & & & \\
\hline $\mathrm{Ni}$ & & & & & & & \\
\hline $\mathrm{C}$ & & & & & & 0,0859 & \\
\hline $\mathrm{P}$ & & & & & & & \\
\hline $\mathrm{S}$ & & & & & & & \\
\hline $\mathrm{Na}$ & & & & & 0,029 & & \\
\hline $\mathrm{Ca}$ & & & & & 0,044 & 0,0460 & \\
\hline $\mathrm{N}$ & & & & & & & 0,780000 \\
\hline $\mathrm{Ba}$ & & & & & & 0,3622 & \\
\hline
\end{tabular}




\section{Kuat Sumber Teras Reaktor RRI-50}

Hasil penentuan kuat sumber radiasi tangkapan radiatif, fisi spontan dan peluruhan produk fisi teras reaktor RRI-50 diplot pada Gambar 3. Pada Gambar 3 tersebut terlihat bahwa, kuat sumber gamma teras reaktor RRI-50 yang paling besar dari energi rendah hingga energi tinggi adalah kuat sumber yang berasal dari proses tangkapan radiatif. Kuat sumber gamma yang paling rendah yang berasal dari proses peluruhan bahan radioaktif di dalam teras reaktor. Pada saat reaktor beroperasi, semua sumber radiasi teras tersebut memberikan kontribusinya dalam paparan radiasi di sekeliling teras.

Pada saat reaktor padam, paparan radiasi di sekitar teras hanya berasal dari proses peluruhan zat radioaktif teras karena proses tangkapan radiatif dan fisi spontan terhenti seketika saat reaktor padam. Dalam mendesain perisai radiasi, harus dapat dipastikan bahwa, bila pada saat reaktor beroperasi, laju dosis di daerah kerja dan lingkungan sekitar masih di bawah batas laju dosis yang dibolehkan, maka saat reaktor padam, laju dosisnya jauh lebih rendah lagi.

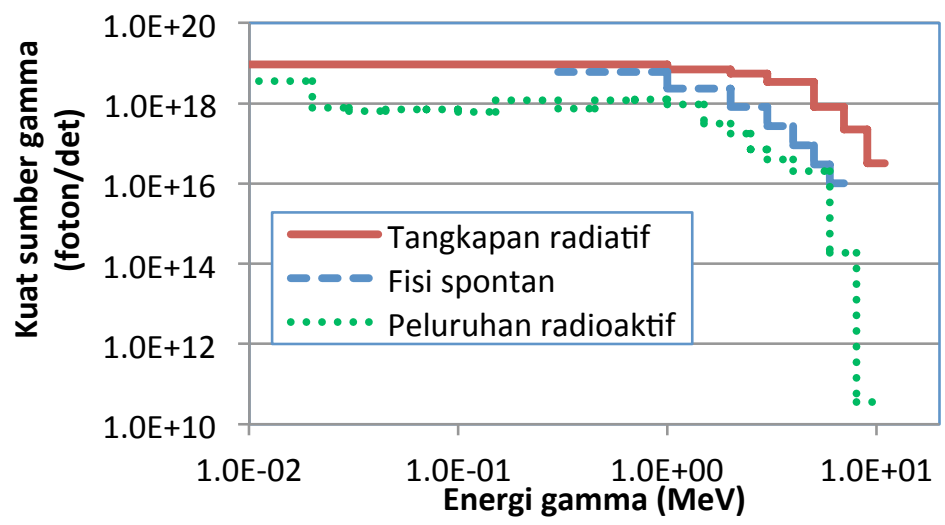

Gambar 3. Kuat sumber radiasi teras RRI-50.

\section{Model Perisai Reaktor RRI-50}

Hasil pemodelan teras reaktor dan susunan perisai radiasi serta tabung berkas neutron reaktor RRI-50 dapat dilihat pada Gambar 4. Seperti yang terlihat pada Gambar 4 tersebut, secara radial, mulai dari teras hingga luar gedung reaktor disarikan jenis dan ketebalan perisai yang terdapat pada reaktor RRI-50 yang dimuat di dalam Tabel 4 dengan total sebanyak 12 lapisan perisai radiasi dengan berbagai jenis dan ukuran.

Tabel 4. Lapisan perisai radial reaktor RRI-50.

\begin{tabular}{clrr}
\hline Daerah & Bahan & Ketebalan $(\mathrm{cm})$ & \\
\hline 0 & Teras reaktor & & 22,29 \\
1 & Air biasa (di dalam bejana teras) & & 7,71 \\
2 & Paduan Al (bejana teras) & 0,50 \\
3 & Paduan Al (tabung air berat) & 0,50 \\
4 & Air berat ( $\left.\mathrm{D}_{2} \mathrm{O}\right)$ & 86,00 \\
5 & Paduan Al (tabung air berat) & 0,50 \\
6 & Gas He & & 19,00 \\
7 & Paduan Al (tabung gas He) & 0,50 \\
8 & Air biasa (kolam reaktor) & & 162,50 \\
9 & Perisai biologi : (beton biasa \& beton berat) & 260,00 \& 0,00 & $100,00 \& 90,00 \quad 0,00 \& 160,00$ \\
10 & Udara (daerah kerja Balai Eksperimen) & 940,00 & 1040,00 \\
11 & Beton biasa (dinding gedung reaktor) & & 50,00 \\
12 & Udara (luar gedung reaktor; lingkungan) & & 50,00 \\
\hline
\end{tabular}

Secara iteratif, ditentukan jenis dan dimensi perisai biologi (lapisan ke-9) yang optimal, yang terdiri dari tiga alternatif, yaitu hanya beton biasa, kombinasi beton biasa dan beton berat serta 
hanya beton berat saja. Sebagai konsekuensinya, daerah kerja Balai Eksperimen (lapisan ke-10) mengalami perubahan mengikuti ketebalan perisai biologi. Komposisi dan kerapatan beton biasa dan beton berat seperti yang dimuat di dalam Tabel 3 di atas. Seperti yang terlihat pada Tabel 4 tersebut, hasil penentuan kombinasi ketebalan perisai biologi beton berat dan beton biasa yaitu 260 dan $0 \mathrm{~cm}, 100$ dan $90 \mathrm{~cm}$ serta 0 dan $160 \mathrm{~cm}$. Pilihan jenis dan dimensi perisai biologi reaktor RRI50 tersebut akan ditentukan diantaranya setelah melalui pertimbangan kekuatan, penataan ruang dan biaya.

Perisai radiasi ke arah aksial di atas teras hanya terdiri dari air biasa yang juga berfungsi sebagai pendingin. Jenis dan dimensi setara perisai radiasi aksial reaktor RRI-50 dimuat di dalam Tabel 5. Hasil analisis menunjukkan bahwa untuk membatasi laju dosis di atas permukaan air di bawah nilai batas yang ditentukan oleh BAPETEN pada kondisi operasi 50 MW yaitu dengan ketinggian air sebesar $1000 \mathrm{~cm}$ dari tengah teras reaktor atau $965 \mathrm{~cm}$ dari permukaan atas teras. Sedangkan ketinggian air kolam minimum yang membuat reaktor terpancung atau scram (trip setting) adalah $800 \mathrm{~cm}$ dari tengah teras. Dan ketinggian air kolam minimum sesaat setelah reaktor padam (shutdown) yang memenuhi batasan laju dosis tersebut adalah $600 \mathrm{~cm}$ dari tengah teras. Udara di balai operasi yang dianalisis adalah $100 \mathrm{~cm}$ dari lantai balai operasi dan saat operasi normal, permukaan air kolam reaktor berada pada $100 \mathrm{~cm}$ di bawah lantai balai operasi seperti terlihat pada Gambar 4 (a).

Tabel 5. Lapisan perisai aksial reaktor RRI-50.

\begin{tabular}{clr}
\hline Daerah & Bahan & Ketebalan $(\mathrm{cm})$ \\
\hline 0 & Teras reaktor & 35,00 \\
1 & Air biasa (di kolam reaktor) & 965,00 \\
2 & Udara (daerah kerja Balai Operasi) & 200,00 \\
\hline
\end{tabular}

Dalam pemanfaatan berkas neutron yang dikeluarkan dari tabung berkas neutron untuk berbagai keperluan penelitian dan neutron radiografi, maka dibuat model tabung berkas tersebut berisi udara. Analisis laju dosis dilakukan saat tabung berkas diisi udara agar diperoleh fluks neutron yang maksimal, namun sebagai konsekueninya paparan radiasi di depan tabung berkas neutron menjadi sangat tinggi. Untuk menjamin keselamatan pekerja, maka dipasang perisai radiasi tambahan di depan tabung berkas neutron tersebut. Model perisai radiasi tambahan di depan tabung berkas neutron yang telah dibuat dapat dilihat pada Gambar 4 (b). Penentuan ketebalan perisai tambahan di depan tabung berkas neutron radial yang berisi udara dilakukan secara iteratif hingga diperoleh ketebalan perisai yang terbuat dari bahan beton biasa setebal $285 \mathrm{~cm}$.

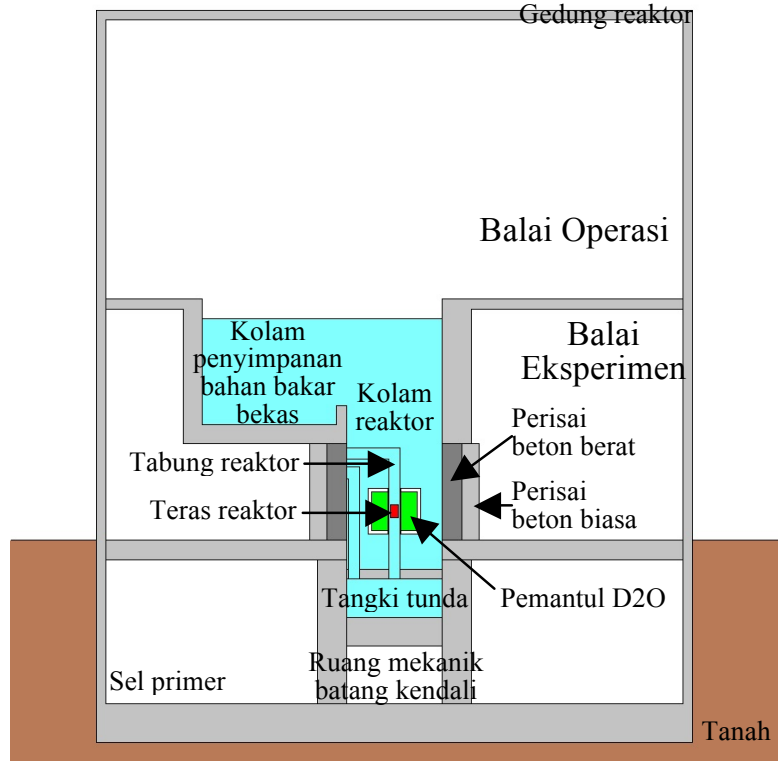

(a)

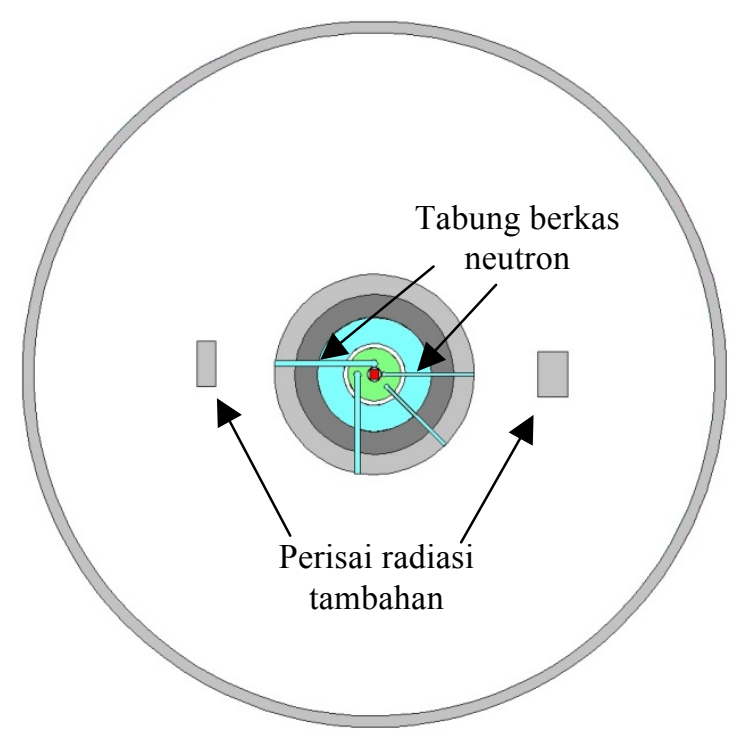

(b)

Gambar 4. Konfigurasi perisai radiasi (a) dan perisai tambahan (b) reaktor RRI-50 


\section{Pengaruh densitas bahan bakar terhadap laju dosis reaktor RRI-50}

Dalam analisis keselamatan radiasi reaktor RRI-50, digunakan tingkat muat yang tertinggi yang pernah diterapkan di dalam reaktor tersebut agar diperoleh hasil analisis yang konservatif. Namun untuk lebih meyakinkan, maka dilakukan analisis pengaruh densitas bahan bakar $3,6 \mathrm{~g} / \mathrm{cm}^{3}$ dan $8,3 \mathrm{~g} / \mathrm{cm}^{3}$ yang hasilnya dapat di lihat pada Gambar 5 yaitu berupa laju dosis di luar perisai biologi reaktor RRI-50. Pada gambar tersebut terlihat bahwa, semakin tinggi tingkat muat atau densitas bahan bakarnya maka kuat sumber teras reaktor akan semakin tinggi yang berakibat pada semakin tinggi paparan radiasi yang dihasilkannya. Bila dibandingkan kuat sumber total teras RRI50 dengan bahan bakar berdensitas $3,6 \mathrm{~g} / \mathrm{cm}^{3}$ dan $8,3 \mathrm{~g} / \mathrm{cm}^{3}$ masing-masing sebesar $3,79 \times 10^{19}$ foton/detik dan $4,89 \times 10^{19}$ foton/detik. Dapat dilihat bahwa semakin tinggi tingkat muat teras reaktor maka semakin tinggi kuat sumbernya demikian pula laju dosis yang dihasilkannya (Gambar 5). Dengan demikian dapat diyakinkan bahwa analisis keselamatan radiasi yang dilakukan pada makalah ini cukup konservatif.

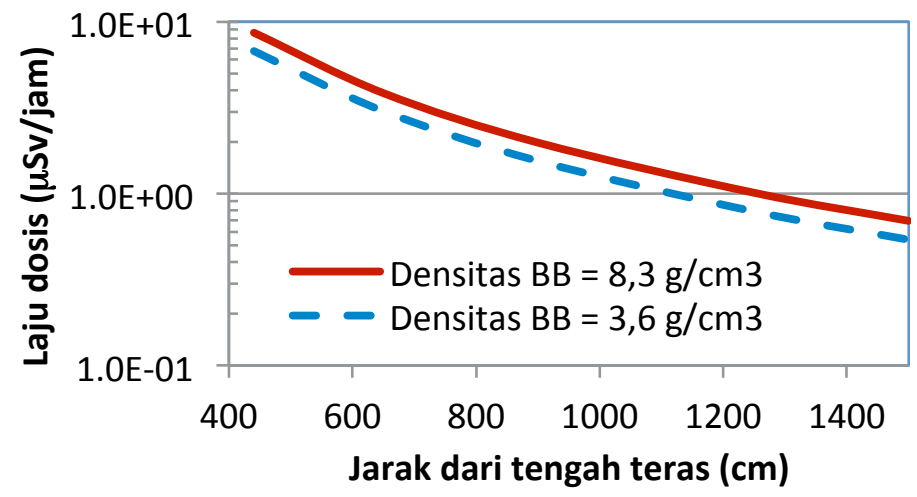

Gambar 5. Pengaruh densitas bahan bakar teras RRI-50 terhadap paparan radiasi gamma di luar perisai radiasi.

\section{Distribusi laju dosis reaktor RRI-50}

Hasil analisis distribusi laju dosis gamma mulai dari kolam pendingin hingga luar gedung reaktor RRI-50 dengan berbagai variasi jenis dan dimensi perisai biologi diplot pada Gambar 6 . Distribusi laju dosis gamma di balai operasi saat reaktor beroperasi dengan beberapa ketinggian permukaan air kolam di plot pada Gambar 7. Hasil penentuan distribusi laju dosis gamma dan neutron di dalam dan di luar tabung berkas radial tanpa dan dengan perisai tambahan di depan tabung berkas masing-masing diplot pada Gambar 8.

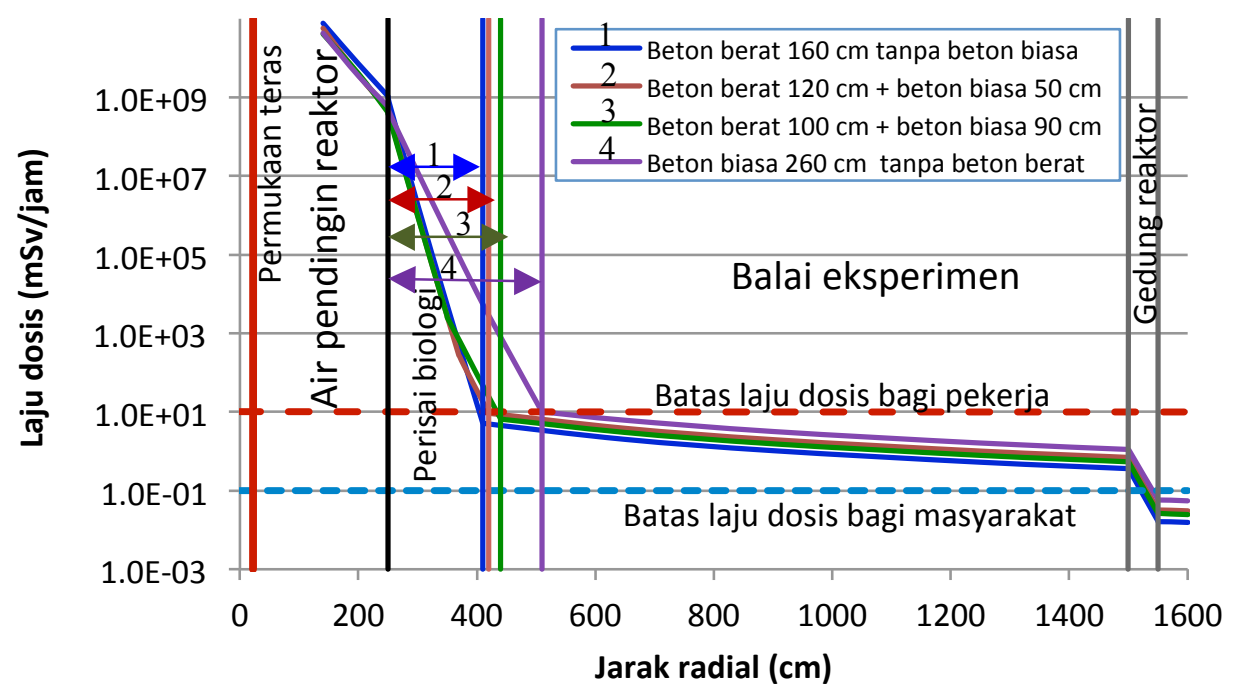

Gambar 6. Distribusi radial laju dosis gamma dengan kombinasi beton berat dan biasa RRI-50. 
Pada Gambar 6 terlihat bahwa laju dosis ketiga kombinasi perisai biologi tersebut dapat mereduksi paparan radiasi reaktor RRI-50 hingga dibawah batas aman bagi pekerja dan masyarakat sekitar. Pada Gambar 6 tersebut terlihat bahwa distribusi laju dosis radial mulai dari dalam kolam pendingin reaktor, perisai biologi, ruang Balai Eksperimen hingga luar gedung reaktor. Desain perisai radiasi yang dibuat tersebut dapat mereduksi laju dosis menjadi $4,2 \mu \mathrm{Sv} / \mathrm{jam}$ di permukaan perisai biologi dan $0,03 \mu \mathrm{Sv} / \mathrm{jam}$ di luar gedung reaktor. Nilai laju dosis tersebut berada di bawah batas keselamatan radiasi yang telah ditetapkan oleh BAPETEN [10] bagi pekerja (maksimal 10 $\mu \mathrm{Sv} / \mathrm{jam}$ ) di Balai Eksperimen dan masyarakat sekitar (maksimal 0,1 $\mu \mathrm{Sv} / \mathrm{jam}$ ). Pilihan jenis dan dimensi perisai biologi reaktor RRI-50 tersebut akan ditentukan melalui pertimbangan kekuatan strukur bangunan, penataan ruang dan biaya.

Pada Gambar 7 diplot distribusi laju dosis di ruang Balai Operasi yaitu $100 \mathrm{~cm}$ di atas lantai dengan variasi ketinggian permukaan air kolam $1000 \mathrm{~cm}$ dan $800 \mathrm{~cm}$ dari tengah teras reaktor. Pada kondisi operasi reaktor normal, ketingian permukaan air kolam reaktor adalah $1000 \mathrm{~cm}$ dari tengah teras ( $965 \mathrm{~cm}$ dari permukaan teras) dengan laju dosis maksimum yang ditunjukkan pada Gambar 6 tersebut sebesar $0,05 \mu \mathrm{Sv} / \mathrm{jam}$. Nilai laju dosis tersebut berada jauh di bawah batas keselamatan radiasi yang telah ditetapkan oleh BAPETEN bagi pekerja di Balai Operasi.

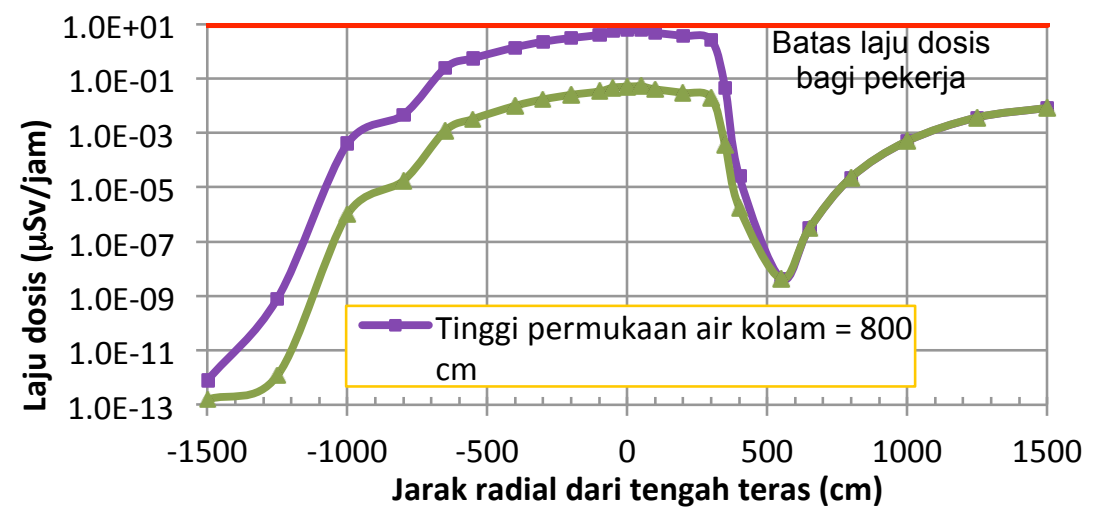

Gambar 7. Distribusi laju dosis saat reaktor beroperasi pada $1 \mathrm{~m}$ di atas lantai Balai Operasi RRI-50.

Pada kondisi tidak normal, apabila terjadi penurunan permukaan air kolam hingga $800 \mathrm{~cm}$ dari tengah teras (765 $\mathrm{cm}$ dari permukaan teras), maka laju dosis maksimum di ruang Balai Operasi sebesar 7,2 $\mu \mathrm{Sv} / \mathrm{jam}$. Nilai laju dosis tersebut sudah mendekati batas keselamatan radiasi yang dibolehkan, maka pada ketinggian air kolam ini operasi reaktor RRI-50 harus dipadamkan. Apabila terjadi penurunan permukaan air kolam yang berlanjut hingga di bawah $800 \mathrm{~cm}$ dari tengah teras sedangkan reaktor masih beroperasi, maka laju dosis di Balai Operasi akan menjadi sangat tinggi sehingga akan membahayakan pekerja. Dengan demikian, harus dipastikan bahwa ketinggian permukaan air kolam reaktor RRI-50 terendah dan reaktor harus dimatikan adalah $800 \mathrm{~cm}$ dari tengah teras (dijadikan trip setting).

Setelah reaktor padam, apabila permukaan air kolam reaktor masih mengalami penurunan, maka ketinggian minimum permukaan air yang dibolehkan adalah $600 \mathrm{~cm}$ dari tengah teras $(565$ $\mathrm{cm}$ dari permukaan teras). Distribusi laju dosis gamma pada saat reaktor dipadamkan di Balai Operasi dengan ketinggian air kolam $600 \mathrm{~cm}$ dari tengah teras reaktor RRI-50 memiliki bentuk distribusi laju dosis seperti pada Gambar 7 namun laju dosis maksimumnya sebesar 1,3 $\mu \mathrm{Sv} / \mathrm{jam}$. Laju dosis saat reaktor padam tersebut akan terus menurun dari waktu ke waktu karena sumber radiasi di teras reaktor mengalami peluruhan. Nilai laju dosis tersebut masih di bawah batas keselamatan radiasi $(10 \mu \mathrm{Sv} / \mathrm{jam})$ yang telah ditetapkan oleh BAPETEN [10] bagi pekerja di Balai Operasi.

\section{Desain perisai radiasi tambahan di depan tabung berkas neutron}

Sebagai reaktor penelitian, diantara utilisasinya seperti penelitian ilmu bahan dan neutron radiografi adalah pemanfaatan berkas neutron melalui tabung berkas neutron. Apabila tabung berkas neutron akan digunakan untuk keperluan tersebut, maka tabung berkas tersebut dibuka dan 
air sebagai isi tabung diganti dengan udara agar neutron dapat keluar dari teras melalui tabung berkas semaksimal mungkin. Sebagai konsekuensi bila isi tabung berkas diganti dengan udara, maka paparan radiasi di depan tabung berkas akan sangat tinggi sehingga akan membahayakan pekerja terhadap radiasi yang keluar. Untuk mengatasi hal tersebut maka didesain perisai tambahan agar paparan radiasi di Balai Eksperimen tetap di bawah batas keselamatan radiasi. Hasil analisis distribusi laju dosis gamma di dalam dan di luar tabung berkas radial dengan dan tanpa perisai tambahan diplot pada Gambar 8.

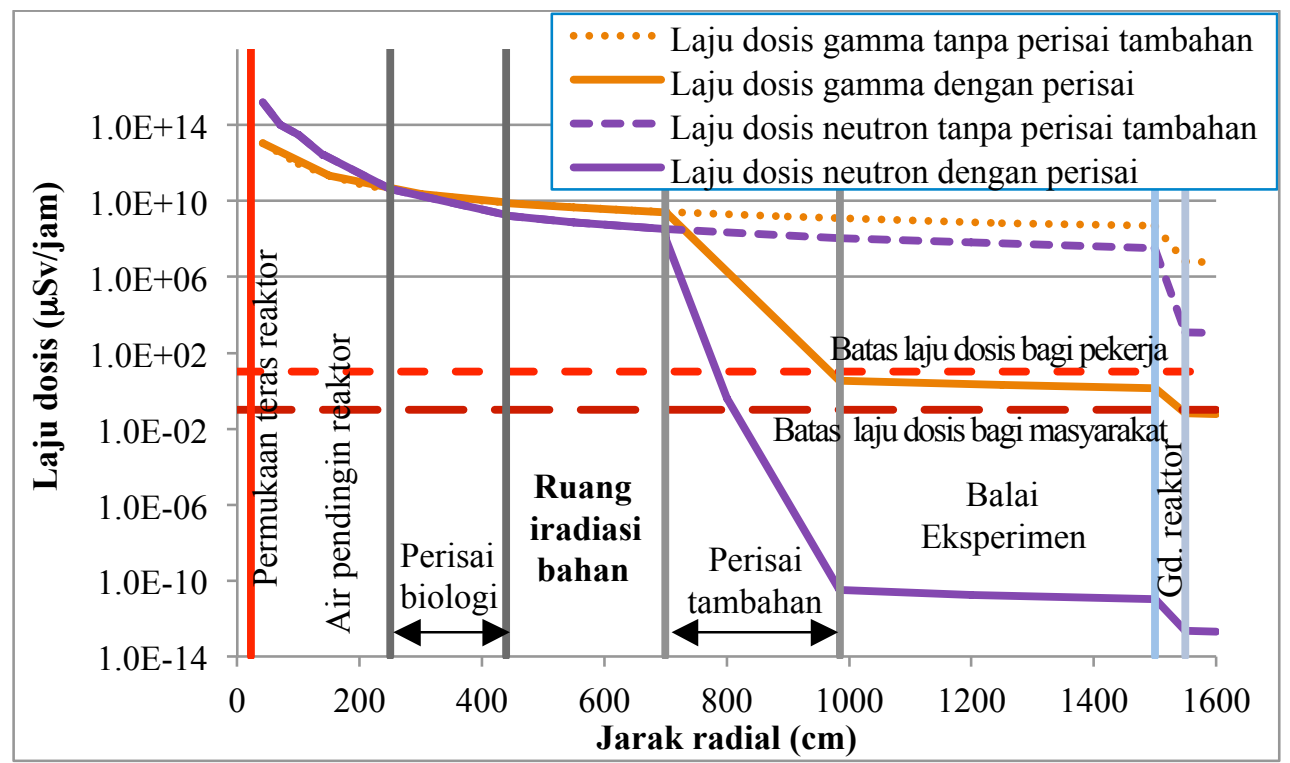

Gambar 8. Distribusi laju dosis gamma dan neutron di dalam dan di luar tabung berkas radial.

Pada Gambar 8 terlihat bahwa apabila tidak dipasang perisai tambahan di depan tabung berkas, maka paparan radiasi gamma dan neutron di depan tabung berkas dan bahkan di luar gedung reaktor sangat tinggi melebihi batas yang ditentukan. Bila sekitar $300 \mathrm{~cm}$ di depan tabung berkas neutron radial yang terbuka di pasang perisai tambahan setebal $280 \mathrm{~cm}$ dapat mereduksi laju dosis gamma menjadi 3,3 $\mu \mathrm{Sv} / \mathrm{jam}$. Nilai laju dosis tersebut masih di bawah batas keselamatan radiasi (10 $\mu \mathrm{Sv} / \mathrm{jam})$ yang telah ditetapkan oleh BAPETEN [10] bagi pekerja di Balai Eksperimen. Seperti yang juga terlihat pada Gambar 8 tersebut, setelah diberi perisai radiasi tambahan, maka paparan radiasi di luar gedung reaktor telah tereduksi hingga di bawah batas laju dosis $(0,1$ $\mu \mathrm{Sv} / \mathrm{jam}$ ) yang diijinkan oleh BAPETEN [10] untuk menjamin keselamatan bagi masyarakat sekitar.

Pada tahun 2012, penulis juga telah melakukan analisis laju dosis neutron di reaktor PLTN PWR 1000 MWe menggunakan program MCNP5 [11]. Pada kasus di reator PLTN, letak perisai biologi sangat dekat dengan bejana tekan yang juga dekat dengan teras reaktor, sehingga mirip dengan kasus tabung berkas neutron yang berisi udara pada reaktor riset. Kemiripan itu terletak pada kenyataan bahwa pancaran radiasi dari teras tidak banyak mengalami hambatan untuk keluar dari teras reaktor kecuali pada perisai biologi dan untuk kasus ini adalah perisai biologi tambahan. Hasil penelitian pada tahun 2012 tersebut dijadikan perkiraan awal dari penentuan ketebalan perisai tambahan namun karena reaktor riset menghasilkan fluks neutron yang lebih tinggi maka desain perisai tambahan sedikit lebih tebal dibandingkan dengan perisai biologi PLTN. Dengan demikian ketebalan perisai tambahan di depan tabung berkas neutron reaktor RRI-50 sebesar $280 \mathrm{~cm}$ merupakan hasil desain yang cukup optimal.

Analisis laju dosis neutron di sepanjang dan di depan tabung berkas neutron saat dibuka pada reaktor RRI-50 selama dilakukan eksperimen dilakukan menggunakan program MCNPX. Perisai radiasi neutron tambahan yang dipasang di depan tabung berkas neutron tidak cukup menggunakan perisai radiasi beton biasa. Karena unsur-unsur di dalam beton tidak banyak yang dapat menahan atau menangkap neutron sehingga radiasi neutron dapat menembus perisai dengan mudah. Sehingga diperlukan unsur-unsur tambahan di dalam perisai radiasi yang dapat menahan atau 
menangkap neutron secara efektif. Diantara unsur-unsur tambahan tersebut yang dapat menangkap radiasi neutron dengan sangat baik adalah boron, cadmium dan lain-lain yang memiliki tampang lintang tangkapan neutron yang besar $[12,13,14]$. Pada penelitian ini digunakan beton yang mengandung senyawa boron $[15,16,17]$ sebagai perisai radiasi tambahan di depan tabung berkas yaitu jenis beton Boron Frits-baryte setebal $280 \mathrm{~cm}$. Hasil analisis distribusi laju dosis neutron di sepanjang dan di luar tabung berkas radial hingga di luar gedung reaktor diplot pada Gambar 8 di atas bersamaan dengan distribusi laju dosis gamma. Pada saat tidak dilakukan eksperimen, tabung berkas diisi air, maka paparan radiasi neutron yang keluar dari tabung berkas menjadi sangat kecil (berorde $10^{-6}$ ) yang jauh dari batas laju dosis yang diijinkan. Hal itu dapat difahami bahwa air juga berperan sebagai perisai neutron yang sangat efektif. Namun pada saat dilakukan penelitian yang memanfaatkan berkas neutron, maka tabung berkas harus dikosongkan agar sebanyak mungkin neutron keluar dari teras reaktor melalui tabung berkas neutron yang akan digunakan dalam eksperimen tersebut. Pada kondisi tersebut, bila tidak dipasang perisai tambahan, maka paparan radiasi neutron di depan tabung berkas manjadi sangat tinggi bahkan hingga di luar gedung reaktor. Setelah dipasang perisai radiasi tambahan, terlihat pada kurva laju dosis neutron tersebut bahwa laju dosis neutron di Balai Eksperimen dan di luar gedung reaktor menjadi sangat kecil yaitu masing-masing berorde $10^{-11} \mu \mathrm{Sv} / \mathrm{jam}$ dan $10^{-14} \mu \mathrm{Sv} / \mathrm{jam}$. Laju dosis di Balai Eksprimen dan di luar gedung tersebut menjadi sangat aman bagi pekerja di Balai Eksperimen dan masyarakat di luar gedung reaktor karena laju dosis radiasinya jauh di bawah batas laju dosis yang ditentukan. Seperti diutarakan di atas, ketentuan di dalam perka BAPETEN dinyatakan bahwa batasan laju dosis maksimal bagi pekerja sebesar $10 \mu \mathrm{Sv} / \mathrm{jam}$ dan bagi masyarakat sekitar sebesar $0,1 \mu \mathrm{Sv} / \mathrm{jam}[10]$.

\section{KESIMPULAN}

Dari hasil penelitian ini dapat disimpulkan bahwa, telah didesain jenis dan dimensi perisai radiasi reaktor RRI-50 yang memiliki kemampuan untuk mereduksi paparan radiasi hingga di bawah batas nilai laju dosis yang ditetapkan oleh BAPETEN bagi pekerja dan mayarakat. Ada beberapa alternatif jenis dan dimensi perisai radiasi yang aman dan penentuan pilihannya masih berkaitan dengan bidang sipil dan ekonomi. Secara aksial, air kolam reaktor, selain sebagai pendingin teras reaktor, juga beperan sebagai perisai radiasi sehingga telah ditentukan ketinggian permukaan air kolam minimal $800 \mathrm{~cm}$ pada saat reaktor beroperasi dan $600 \mathrm{~cm}$ saat reaktor padam agar terjamin keselamatan radiasi bagi pekerja. Secara radial, selain air kolam reaktor dengan diameter $250 \mathrm{~cm}$, kombinasi $90 \mathrm{~cm}$ beton berat dan $60 \mathrm{~cm}$ beton biasa merupakan jenis dan bentuk perisai reaktor RRI50 yang paling optimum untuk menjamin keselamatan radiasi bagi pekerja dan linkungan. Penempatan perisai tambahan dengan jenis jenis beton Boron Frits-baryte setebal $280 \mathrm{~cm}$ berjarak $300 \mathrm{~cm}$ di depan tabung berkas neutron radial saat dilakukan penelitian yang menggunakan berkas neutron juga diterapkan untuk mereduksi paparan radiasi gamma dan neutron hingga di bawah batas yang ditentukan oleh BAPETEN bagi pekerja dan masyarakat diluar gedung reaktor.

\section{UCAPAN TERIMAKASIH}

Pada kesempatan ini penulis mengucapkan terima kasih yang tak terhingga kepada Kepala PTKRN-BATAN dan Kelapa BFTR yang telah memberikan kesempatan dan bantuan moril serta materil berupa dana dari DIPA PTKRN serta semua fihak yang tak dapat disebutkan satu persatu sehingga penulis dapat menyelesaikan penelitian dan penulisan makalah ini.

\section{DAFTAR PUSTAKA}

1. Amir Hamzah, Desain Awal Perisai Radiasi Dan Analisis Laju Dosis Di Daerah Kerja Reaktor Riset Inovatif Menggunakan MCNPX. Prosiding Seminar Nasional ke-19 
Teknologi dan Keselamatan PLTN Serta Fasilitas Nuklir; 2013 24-25 Sep, Yogyakarta; 2013.p. 266-275

2. Tukiran S., at. all. Desain Konseptual Teras Reaktor Riset Inovatif Berbahan Bakar Uranium Molibdenum Dari Aspek Neutronik. Jurnal Teknologi Reaktor Nuklir, Tri Dasa Mega, ISSN 1411-240X 2012; 14, No.3, Oktober: 178-191

3. Rokhmadi, Tukiran S. Efek Densitas Bahan Bakar Terhadap Parameter Koefisien Reaktivitas Teras RRI. Jurnal Teknologi Reaktor Nuklir, Tri Dasa Mega, ISSN 1411-240X 2013; 15, No.2, Juni: $77-89$

4. Sukmanto Dibyo, Endiah P.H, Ing. Djoko Irianto. Analisis Desain Proses Sistem Pendingin Pada Reaktor Riset Inovatif 50 MW. Jurnal Teknologi Reaktor Nuklir, Tri Dasa Mega, ISSN 1411-240X 2015; 17, No.1, Februari: 19-30

5. Iman Kuntoro, Tagor Malem Sembiring. Desain Teras Alternatif Untuk Reaktor Riset Inovatif (RRI) Dari Aspek Neutronik. Jurnal Teknologi Reaktor Nuklir, Tri Dasa Mega, ISSN 1411-240X 2014; 16, No.1, Februari: 1-10

6. Setiyanto. Desain Teras Reaktor Riset Inovatif (RRI). Estimasi Dan Analisis Distribusi Panas Gamma. Jurnal Teknologi Reaktor Nuklir, Tri Dasa Mega, ISSN 1411-240X 2014; 16, No.3, Oktober: 160-168

7. Yuan Luzheng and Kang Yalun, Problems Concerned In Fuel Design of CARR, Presented at the 1998 International Meeting on Reduced Enrichment for Research and Test Reactors; 1998 Oct 18-23. São Paulo, Brazil

8. Meiyin Zheng et. all. Development of a MCNP-ORIGEN burn-up calculation code system and its accuracy assessment. Ann Nucl. Energy 2014; 63: 491-498

9. Ardani. Evaluasi Dosis Gamma Akibat Penurunan Permukaan Air Kolam RSG-GAS. Jurnal Teknologi Reaktor Nuklir, Tri Dasa Mega, ISSN 1411-240X 2007; 9, No.2, Juni: 51-64

10. Bapeten. Proteksi dan Keselamatan Radiasi Dalam Pemanfaatan Tenaga Nuklir. Perka Nomor 4 tahun 2013. BAPETEN; 2013

11. Amir Hamzah. Analisis Laju Dosis Neutron Reaktor PLTN PWR 1000 MWe Menggunakan Program MCNP. Jurnal Teknologi Reaktor Nuklir, Tri Dasa Mega, ISSN 1411-240X 2012; 14, No.2, Juni: $65-75$

12. Berna Oto, at. all. Neutron shielding qualities and gamma ray buildup factors of concretes containing limonite ore. Nucl. Eng. Design 2015; 293: 166-175

13. Alia Alizadeh, Amir Saeid Shirani, Samira Kashi. Neutron and gamma-ray deep penetration calculation through biological concrete shield of VVER-1000 reactor by a new technique based on variance reduction. Ann. Nucl. Energy 2013; 60: 86-92

14. Osman Gencel, at. all. Determination and calculation of gamma and neutron shielding characteristics of concretes containing different hematite proportions. Ann. Nucl. Energy 2011; 38: 2719-2723

15. D. Sariyer, R. Küçer, N. Küçer. Neutron Shielding Properties of Concretes Containing Boron Carbide and Ferro - Boron. World Conference on Technology, Innovation and Entrepreneurship, Procedia - Social and Behavioral Sciences 2015; 195: 1752 - 1756

16. I. Akkurt, A.M. El-Khayatt. The effect of barite proportion on neutron and gamma-ray shielding. Ann. Nucl. Energy 2013; 51: 5-9

17. Mario Matijevic', Dubravko Pevec, Krešimir Trontl. Boration modeling of the PWR biological shield using SCALE6.1 hybrid shielding methodology. Ann. Nucl. Energy 2015; 85: 979-994 